УДК 331.104

СОЦИАЛЬНО-ЭКОНОМИЧЕСКИЕ ФАКТОРЫ, ОПРЕДЕЛЯЮЩИЕ ИЗМЕНЕНИЕ СИСТЕМЫ ТРУДОВОЙ МОТИВАЦИИ В НОВЫХ СОЦИАЛЬНО-ЭКОНОМИЧЕСКИХ И ТЕХНОЛОГИЧЕСКИХ УСЛОВИЯХ В БЕЛАРУСИ*

\title{
С.Ю. СОЛОДОВНИКОВ
}

д-р экон. наук, профессор, заведующий кафедрой «Экономика и право»

Белорусского национального технического университета, г. Минск

\section{Аннотация}

Установлены и раскрыты сочиально-экономические факторы, обусловливаюшие изменение системы трудовой мотиваиии в новых сочиально-экономических и технологических условиях. Содержательно охарактеризованы предпосылки, причины и условия эволюции трудовой мотивачии в новых условиях хозяйствования. белорусского государства.

Ключевые слова: труд, трудовые отношения, разделение труда, инновачионное развитие, экономические интересы, НТР, переходная экономика, белорусская экономика.

\section{Abstract}

The article revealed socioeconomic factors that contribute to the change of motivation system in the new socio-economic and technological conditions. Informally described background, the causes and conditions of the evolution of labor motivation in the new economic conditions. Belarusian state.

Key words: labor, labor, division of labor, innovative development, economic interests, STR, transition economy, the Belarusian economy

\section{ВВЕДЕНИЕ}

В современном обществоведении, в том числе в политической экономии, не принято разделять социально-экономические факторы, на обусловливающие возникновение какого-либо экономического феномена и на предопределяющие его дальнейшее развитие, эволюцию. Такое разделение, предложенное О. Контом и Г. Спенсером, а позднее

* Статья подготовлена в рамках реализации договора с БРФФИ на выполнение научноисследовательской работы по теме «Трансформация системы трудовой мотивации в условиях модернизации экономики Республики Крым Российской Федерации и Республики Беларусь» договор с БРФФИ № Г15Р-035 от «04» «мая» 2015 г. 
доведенный до логического завершения в рамках ортодоксального марксизма, сегодня признано неправомерным, поскольку в его основу положено некорректное, излишнее отождествление биологических и социальных объектов. Как результат конечный итог развития общества у О. Конта «опять таки уподоблялся результату эволюции организма (от эмбриона к зрелости). - справедливо отмечает П. Штомка. Предполагалось, что существует некое устойчивое состояние общества, которое можно наблюдать и анализировать независимо от состояния последнего» [1, с. 19]. Г. Спенсер развил социальную парадигму О. Конта, изменив терминологию и противопоставив «структуру» и «функцию», при котором «понятие «структура» подразумевало исследование внутреннего строения, или формы, социального целого, понятие «функции» - способы его деятельности, или трансформации» [1, с. 19]. Из названного подхода вытекало, что возможно отделить структуру общества от его функций и что социум можно рассматривать «как некую жесткую сущность, осязаемый объект, отдельно от происходящих в нем процессов» [1, с. 19]. В то время как общество - это «выделившееся из природы системное образование, представляющее собой исторически изменяющуюся форму жизнедеятельности людей, которая проявляется в функционировании и развитии (выделено мной - С.С.) социальных институтов, организаций, общностей и групп, отдельных индивидов» [2, с. 579]. Исходя из приведенного определения явствует, что процессы общественной жизнедеятельности, включают в себя одновременно и функционирование и развитие.

\section{РЕЗУЛЬТАТЫ И ИХ ОБСУЖДЕНИЕ}

Система трудовой мотивации, как и любое иное реальное общественное явление, не может быть первоначально рассмотрено в статике, а затем уже в динамике, поскольку и происхождение, и функционирование, и изменение любых социальных объектов это непрерывный, не прекращающийся процесс жизни, который можно лишь условно (мысленно, абстрактно) и для достижения определенных научных целей разделять на некие идеальные периоды или состояния.

Очевидно, что система трудовой мотивации непрерывно, постоянно, с той или иной быстротой, эволюционирует, т.е. в ней происходят процессы изменения (преимущественно необратимого характера). Как известно, в результате эволюции возможно усложнение, дифференциация, повышение уровня организации системы или же наоборот, понижение этого уровня. Применительно к заявленной теме нашего исследования в случае успешной модернизации национальной экономики, которая будет сопровождаться как ростом хозяйственных укладов, так и усилением 
вариабельности экономического поведения социально-экономических субъектов, количество которых также будет возрастать (подробнее об этом написано в книге Солодовников С.Ю. «Классы и классовая борьба в постиндустриальном обществе» [3, с. 379]) должно происходить усложнение системы трудовой мотивации. Следует также отметить, что усиление процессов глобализации и регионализации, существующие глобальные цивилизационные, технологически и политико-экономические тенденции выдвигают все новые и новые требования к хозяйственному механизму в контексте усиления конкурентоспособности национальной экономики и отдельных коммерческих организаций. Это в свою очередь требует соответ- ствующей эволюции системы трудовой мотивации, адаптации ее к новым глобальным, региональным и национальным политико-экономическим реалиям.

Социально-экономические факторы, определяющие изменение системы трудовой мотивации в новых социально-экономических и технологических условиях в Беларуси можно условно разделить на три группы: условия, предпосылки и причины. Все эти названные социальноэкономические факторы непосредственно связаны друг с другом и взаимообусловлены.

В качестве условий, предопределяющих изменения системы трудовой мотивации, выступают: глобализация; либерализация рынков товаров и услуг; доминирование в мировой экономике глобальных финансов; концентрация капитала; социальный характер белорусского государства.

Соответственно в качестве предпосылок изменения системы трудовой мотивации в новых социально-экономических и технологических условиях следует выделять: изменение системы приоритетов деятельности предприятий (коммерческих организаций) в условиях преимущественно рыночной экономики, пришедшей на смену административно-командной советской системе; множественность форм собственности, пришедшая на смену доминированию государственной формы собственности в СССР; изменение в постсоветский период форм и методов управления коммерческими организациями, находящимися в государственной собственности; на первый план, «как исполнители задачи структурной модернизации, вышли экономические агенты, оперирующие в реальном секторе. Именно от их заинтересованности в эффективном ведении дел зависит результат решения стратегических национальных задач» [4, с. 9]; наделение субъектов реального сектора экономики широким спектром прав участника ВЭД, что стало необходимым для того, чтобы они могли «вписаться в современную глобальную экономику и эффективно взаимодействовать с внешней средой» [4, с. 9]. 
В качестве причин изменения системы трудовой мотивации в новых социально-экономических и технологических условиях следует выделять: научно-техническая революция, обусловливающая смену технологических укладов; усиление социально-классовой дифференциации в обществе; развитие и широкое распространение общественно-функциональных технологий, позволяющих навязывать работникам псевдомотивы, отвечающие интересам не их носителей, а манипуляторов; потеря рыночным хозяйственным укладом доминирующего положения в национальных экономических системах и в международных экономических отношениях, что существенно нарушает рыночные принципы оплаты и стимулирования труда; постоянное усиление государства как конфигуратора социально-трудовых отношений; ослабление материальных стимулов к труду и усиление не материальных стимулов.

Модель, под которой нами понимается идеальное воспроизведение в знаковой форме принципов функционирования и развития системы воздействия всех вышеназванных факторов на систему трудовой мотивации схематически отражена на рисунках: 1 «Принципы действия социально-экономических факторов, определяющих изменение системы трудовой мотивации в новых социально-экономических и технологических условиях в Беларуси» и 2 «Механизм действия социально-экономических факторов, обусловливающих изменение системы трудовой мотивации в новых социально-экономических и технологических условиях в Беларуси», рисунки 1 и 2. 


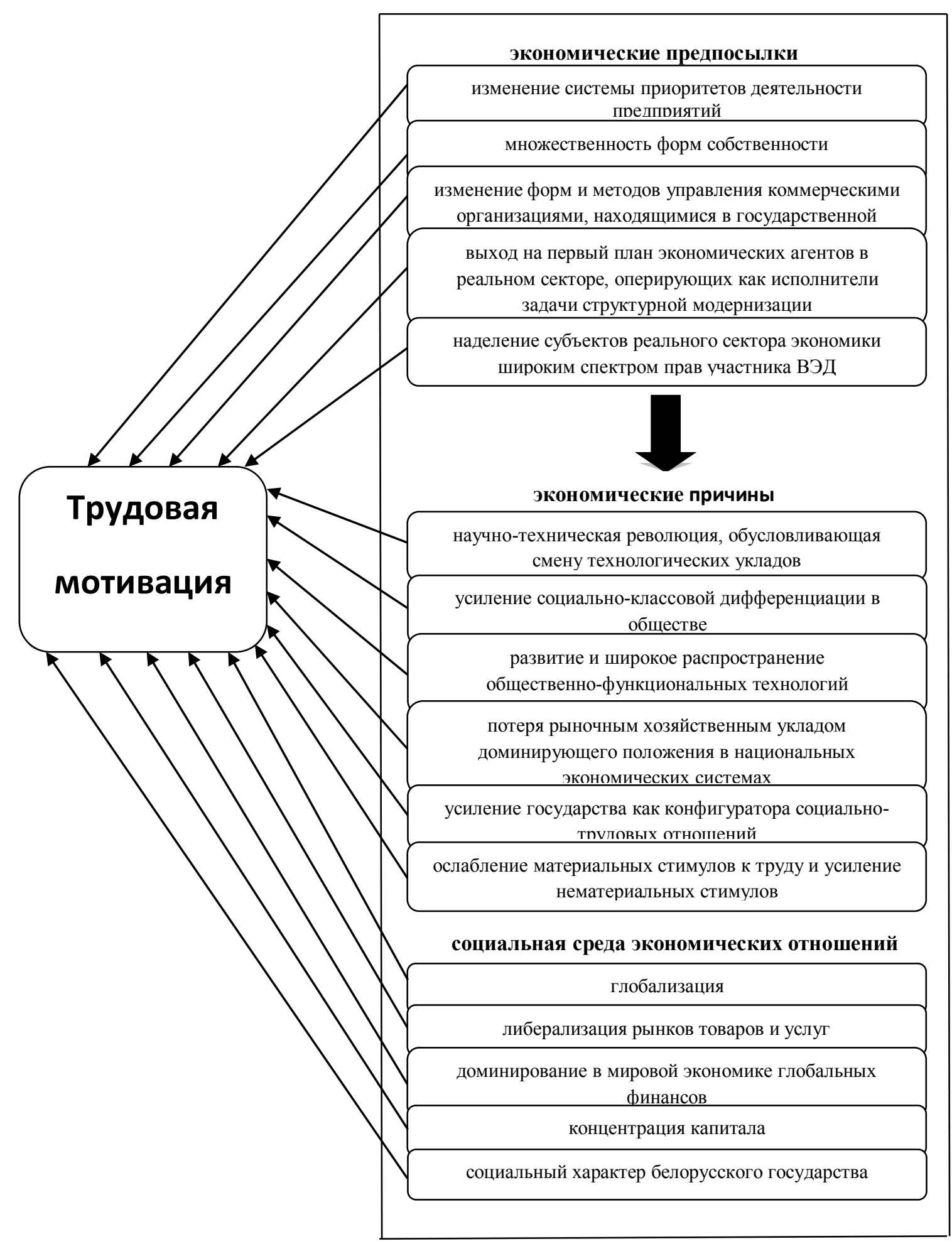

Рисунок 1 - Принципы действия социально-экономических факторов, определяющих изменение системы трудовой мотивации в новых социально-экономических и технологических условиях в Беларуси 


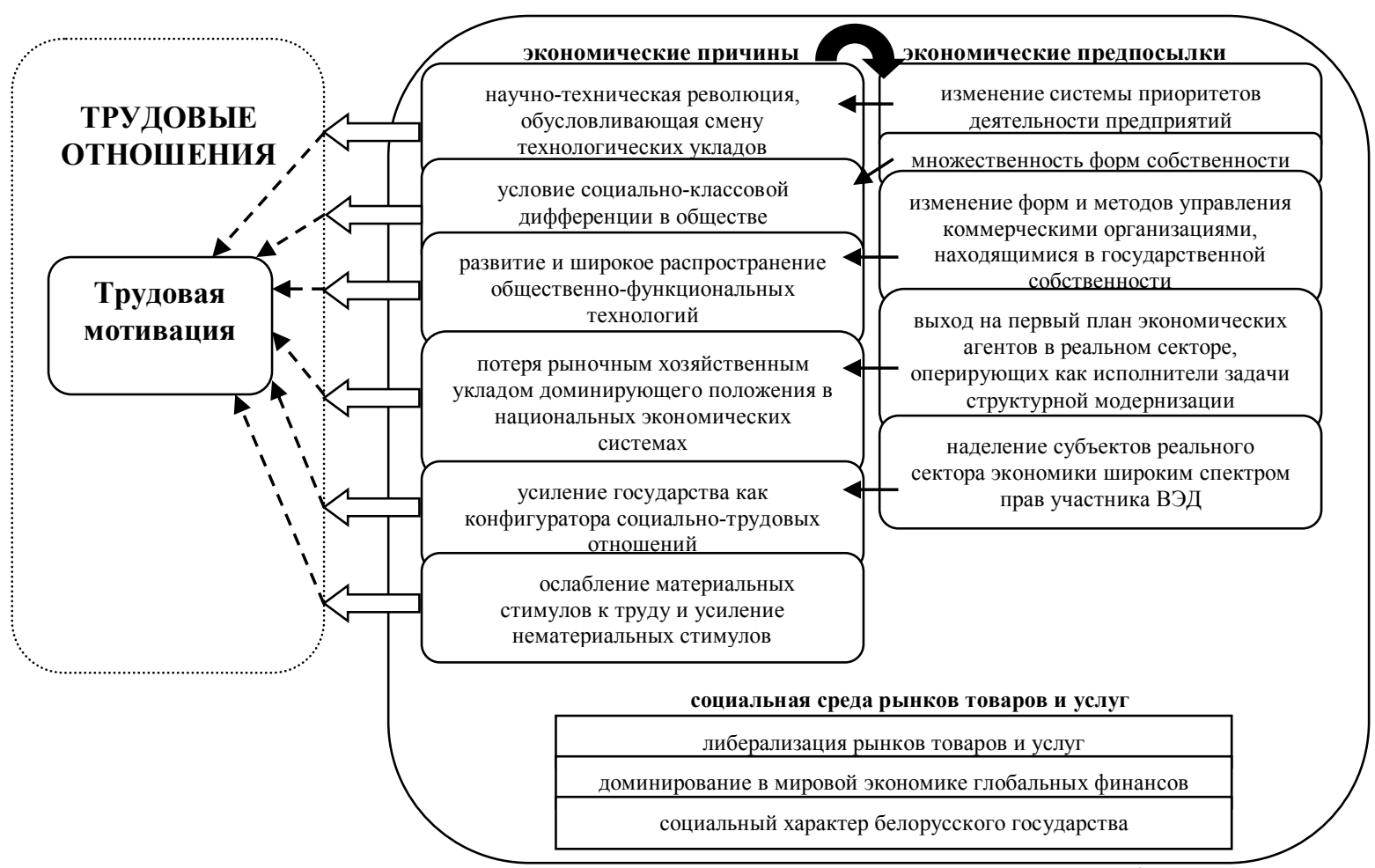

Рисунок 2 - Механизм действия социально-экономических факторов, обуславливающих изменение системы трудовой мотивации в новых социально-экономических и технологических условиях в Беларуси

Как видно из названных рисунков условия, предопределяющие изменение системы трудовой мотивации в новых социальноэкономических и технологических условиях выступают относительно внешними факторами по отношению к экономической системе общества, создавая среду, в которой возникают, существуют и развиваются предпосылки и причины изменения системы трудовой мотивации. Соответственно влияние глобализации, либерализация рынков товаров и услуг, концентрация капитала, социальный характер белорусского государства, т.е. оказывают воздействие на систему трудовой мотивации в Республике Беларусь опосредовано, через достаточно тонкий механизм трансформации предпосылок и причин, обусловливающих эволюцию данной системы. Тем не менее опосредованный характер такого воздействия не означает, что их влияние незначительно. Скорее речь надо вести о том, что действие социально-экономических факторов, определяющих изменение системы трудовой мотивации в новых социально-экономических и технологических условиях в Беларуси в случае в зависимости от того условия это, либо предпосылки и причины, также различается по времени. Влияние условий, как фактора, требует относительно большего времени.

В качестве первого (главного) фактора, определяющего изменение системы трудовой мотивации в новых социально-экономических и технологических условиях, выступает научно-техническая революция, 
обусловливающая смену технологических укладов. «Технологический уклад, - как справедливо отмечает О.А. Наумович, - это определенный тип производственных отношений, существующий наряду с другими в данной экономической системе. $<\ldots>$ уклад представляет собой группу хозяйственных единиц, однородных по технике и организации производства, типу производственных отношений и вовлеченных вследствие этого в уклад одного механизма определенного типа воспроизводства в период индустриализации, так как отдельные хозяйственные единицы из разных укладов могут иметь довольно развитые рыночные связи, в том числе внеукладные.» [5, с. 7]. По существу технологический уклад представляет собой исторически определенную форму институциональной фиксации не случайных, сущностных, регулярно повторяющихся связей и отношений между индивидами объединенными в относительно обособленную социально-экономическую систему (которая в свою очередь является компонентом экономической системы общества) для которой характерно обеспечение собственного воспроизводства на основе определенных технических и/или организационно-функциональных технологий. По мере развития общества, возрастание значения научно-технического прогресса, количество технологических укладов возрастает. В результате этого на сегодняшний день экономики всех экономически развитых и транзитивных стран являются многоукладными.

По мере ускорения НТП, приведшего к НТР, смена доминирующих технологических укладов происходит все быстрее. В настоящее время в очередной раз наблюдается эта смены в мировой экономике. Как отмечают по этому поводу ведущие российские экономисты: «всплеск и падение цен на энергоносители, мировой финансовый кризис - верные признаки завершающей фазы жизненного цикла доминирующего технологического уклада и начала структурной перестройки экономики на основе следующего уклада» [6, с. 17]. В результате этого институциональная фиксация отношений между индивидами, входящими в новые высокотехнологические уклады, менее устойчивая, чем между индивидами, входящими в традиционные уклада. Последнее объясняется тем, что в традиционных укладах названная фиксация зачастую носит явно выраженный классовый характер, продолжалась на протяжении нескольких поколений и в результате часто принимает форму традиций и обычаев. В новых (высокотехнологических и иных) укладах на формирование этой институциональной фиксации исторически было отведено меньше времени, поэтому межсубъектные отношения в таких технологических укладах менее устойчивы. Последнее с одной стороны создает предпосылки для все более ускоряющейся смене новейших 
технологических укладов, в с другой снижает социально-экономическую силу классов, существование которых основывается на включении индивидов в них входящих в высокотехнологические уклады.

НТР влияет на изменение системы трудовой мотивации через эволюцию институтов трудовой мотивации в для которой, как нами уже отмечалось ранее, следующие, иногда противоположные, тенденции: адаптация действующих институтов трудовых отношений к изменяющимся господствующим технологическим укладам; переход от индустриального к сверхиндустриальному обществу с развитой сферой услуг; переходом к новейшим технологическим укладам; усиления рыночных элементов в экономике; усиление неформальных норм в сфере трудовых отношений по сравнению с формальными; неравноправие экономических субъектов в сфере труда; усиление влияния социального капитала на формирование трудовых отношений в коммерческих организациях; развитие эффективной системы мотивации за счет гибкости внутрифирменных контрактов позволяющих успешнее комерциализировать человеческий капитал работников, формирование института работников-инноваторов; формирование и развитие института общественно-государственно-частного партнерства в сфере трудовых отношений; формирование регулируемого гибкого рынка труда; развитие системы непрерывного образования; влияние глобализации; усиление рисков влияния на систему трудовой мотивации современного информационного оружия, применяемого как на мегосударственном уровне, так и на микро-уровне; усиление информационного неравенства в сфере трудовых отношений; формирование посткапиталистических трудовых отношений; дальнейшее развитие механизмов самозанятости.

В качестве второго фактора, определяющего изменение системы трудовой мотивации в новых социально-экономических и технологических условиях выступает усиление социально-классовой дифференциации в обществе. Сформировавшееся сегодня в экономически и технологически развитых государствах (большинство стран ЕС, Северная Америка, Япония, Австралия, Новая Зеландия и некоторые другие) постиндустриальное общество радикально изменило социально-классовую структуру общества. Здесь следует оговориться, что в рамках данной работы нами под постиндустриальным обществом понимается высокотехнологически и социально-экономически развитый социум, пришедший на смену индустриальному обществу. При таком подходе нами преднамеренно отождествляются постиндустриальные и сверхиндустриальные экономические системы. Несмотря на то, что между последними существуют серьезные феноменологические развития, такое 
абстрагирование методологически допустимо в рамках исследования процессов социально-классовой дифференциации в них сегодня происходящих.

Усиление многоукладности в постиндустриальном обществе, сопровождаемое увеличением количества периферийных социальноэкономических укладов и ускорением трансформация доминирующих укладов, ведет к значительному усложнению социально-экономических отношений. При этом наблюдается усиление профессиональноквалификационного расслоения общества, затрудняется перемена труда между различными квалификационно-профессиональными группами, между индивидами занятыми в информационной и традиционной экономиками и т.д. Названные процессы в странах «золотого миллиарда» происходят на фоне и при непосредственном влиянии повышенной (по сравнению с традиционными и индустриальными обществами) динамикой постиндустриальной экономической системы и ростом доли сектора услуг в создании, распределении и перераспределении общественного богатства. Не последнюю роль в этом перераспределении в пользу высших классов играют глобальные финансы.

В 1960-90-х годах прошлого века в странах золотого миллиарда сформировался новый тип обывателя, обывателя сытого и самодовольного, который в период этих благодатных пятидесяти лет (европейского «золотого века»), когда финансовые и политические элиты капиталистических стран были вынуждены, борясь с социалистической идеей, делиться частью своих сверхприбылей со своими согражданами... ${ }^{1}$ В результате новый европейский обыватель, вооруженный идеями протестантского фундаментализма и «общечеловеческими» ценностями, не заметил, что социальные лифты в ЕС давно перестали работать, а децильные коэффициенты достигли заоблачных высот, по сравнению с которыми имущественная дифференциация в Римской империи кажется образцом социальной справедливости. Децильный коэффициент в Великобритании сегодня равняется 100! Золотой век в Западной Европе закончился, закончился в ней и период латентных экономических конфликтов. По мере снижения европейской конкурентоспособности и усиления поляризации в странах ЕС будут усиливаться в них и между ними социально-классовые конфликты.

Следует отметить, что в свое время С.Ю. Солодовниковым была доказана обоснованность выделения трудовых отношений в качестве первого фактора, обуславливающего существование и эволюцию социально-классовой структуры общества, что оправдано по следующим

\footnotetext{
1 В качестве примера достаточно вспомнить события 1968 года во Франции и последовавшие за этим изменения в социальной политике этой страны.
} 
причинам: во-первых, генетически (исторически) именно трудовые отношения лежат в основе дифференциации индивидов как носителей определенных трудовых функций, а уже на основе этого возникала их дифференциация как собственников. Тем не менее, не упуская из виду эти важные соображения, не следует забывать, что в социумах с развитой социально-классовой дифференциацией, занятие индивидами теми или иными видами трудовой деятельности можно достаточно просто объяснить через принадлежность их к тем или иным имущественным группам, то есть местом в отношениях собственности. Хотя, при корректном генетическом подходе, проблема остается прежней, так как место субъектов в имущественной структуре само является дериватом трудовых отношений. Более того, при детерминировании экономической системы трудовыми (продукционными) интересами индивиды наделяются прерогативами собственников (или являются собственниками) именно в той мере, в какой это необходимо для выполнения ими определенных трудовых функций; во-вторых, исторический опыт показывает, что если класс собственников не может полностью (иногда частично) выполнять какие-то социально-значимые трудовые функции, то он вынужден либо погибнуть, либо привлечь к выполнению этих социально-значимых функций представителей иных социально-классовых образований, отдав затем де-факто (а часто и де-юре) частично или полностью им свои прерогативы собственников ${ }^{2}$.

Основываясь на этом подходе можно сделать вывод, что по мере проведения технологической модернизации экономики, которая будет способствовать усложнению социально-классовой структуры общества (прежде всего за счет роста социально-трудовой дифференциации на основе увеличения разнообразия профессионально-квалификационных групп) и может затруднять перемену труда как результата присвоения привилегированными классами важнейших экономических, социальных и политических функций. Такая ситуация ставит достаточно жесткие границы в карьере для представителей большинства классов, что значительно влияет на их трудовую мотивацию. Поскольку в «обществе всеобщего благоденствия» для большинства населения нет угрозы не только голода, но и нищеты (в классическом понимании этого понятия), а переход в высшие классы становится практически невозможным, то многие люди стремятся выражаться не в профессиональной деятельности, а в иных формах неагрессивной социальной активности (волонтерское движение, участие в художественной самодеятельсности и т.д.), что негативно сказвается на развитии реальной экономики.

2 Подробнее смотри: Солодовников С.Ю. Классы и классовая борьба в постиндустриальном обществе: методологические основы политико-экономического исследования. - Минск : БНТУ, 2014. - 378c. 
В Республике Беларусь социально-классовая дифференциация основывается сегодня, прежде всего на различиях места индивидов в социально-трудовых отношениях, а уже во вторую очередь на различиях в отношениях собственности. В условиях социального государства несколько сглаживается имущественное расслоение и проблема имущественного достатка для большинства населения еще не решена, поэтому социально-классовая дифференциация в меньшей мере влияет на трудовую мотивацию.

В качестве третьего фактора, определяющего изменение системы трудовой мотивации в новых социально-экономических и технологических условиях, выступает развитие и широкое распространение общественнофункциональных технологий, позволяющих навязывать работникам псевдомотивы, отвечающие интересам не их носителей, а манипуляторов. Действие этого фактора обусловливается тем, что сегодня создана самая совершенная в истории человечества система идеологического «зомбирования» населения в постиндустриальных и иных странах препятствующая осознанию большинством населения своих групповых интересов. В результате чего названные технологии, наиболее развитые в странах золотого миллиарда, выступают инструментами подмены реальных экономических мотивов (основанных на потребностях и интересах субъекта) на псевдо мотивы за счет современных способов информационно-идеологического убеждения (через интернет технологии и традиционные СМИ), что порождает у объекта воздействия поведение идущее в разрез с его потребностями, потребностями группы и класса к которым он принадлежит, общества в целом.

В качестве четвертого, пятого и шестого факторов, определяющих изменение системы трудовой мотивации в новых социальноэкономических и технологических условиях выступают потеря рыночным хозяйственным укладом доминирующего положения в национальных экономических системах и в международных экономических отношениях, что существенно нарушает рыночные принципы оплаты и стимулирования труда; постоянное усиление государства как конфигуратора социальнотрудовых отношений; ослабление материальных стимулов к труду и усиление не материальных стимулов. Названные факторы тесно взаимосвязаны и взаимообусловлены. Так в результате потери рыночной системой хозяйствования доминирующего положения в национальной и мировой экономике и усиления роли государства как социального гаранта и конфигуратора трудовых отношений снижается значение материальных стимулов к труду. Вместе с тем снижение материальных стимулов к труду также понижается по мере расширения возможностей у низших и средних классов получать средства, необходимые им для 
устраивающего их существования и поддержания приемлемого для них уровня жизни помимо непосредственного участия в трудовом процессе. Также наблюдается тенденция к возможности выбора альтернативных занятий, примерно с одинаковым доходом, но с различной психологической привлекательностью - в результате люди могут выбирать работу не по причине необходимости обеспечить себя и семью средствами для существования, а по тому, что им больше нравится.

\section{ВЫВОДЫ}

Установлены социально-экономические факторы (подразделяющиеся на предпосылки, причины и условия), определяющие изменение системы трудовой мотивации в новых социально-экономических и технологических условиях. В качестве названных причин выступают: НТР и смена технологических укладов, усиление социально-классовой дифференциации, развитие общественно-функциональных технологий, потеря рыночным хозяйственным укладом доминирующего положения, усиление государства как конфигуратора социально-трудовых отношений, ослабление материальных стимулов к труду и усиление не материальных стимулов. Названные причины предопределены такими предпосылками как: изменение экономических приоритетов деятельности предприятий (в том числе государственных) в переходной экономике, множественность форм собственности, необходимость структурной модернизации реального сектора экономики. При этом условиями выступают: глобализация; либерализация рынков товаров и услуг; доминирование в мировой экономике глобальных финансов; концентрация капитала; социальный характер белорусского государства.

\section{ЛИТЕРАТУРА}

1. Штомпка П. Социология социальных изменений. - М.: Аспект Пресc, 1996.

2. Большой энциклопедический словарь: философия, социология, религия, эзотеризм, политэкономия / Главн. науч. ред. и сост. С.Ю. Солодовников.- Мн.: МФЦП, 2002. - 1008c.

3. Солодовников С.Ю. Классы и классовая борьба в постиндустриальном обществе: методологические основы политикоэкономического исследования / С.Ю. Солодовников ; Минск: БНТУ, 2014.

4. Абузярова Э.Р. Институциональные основы реального сектора экономики // Экономические науки. - 2015. - №7(128). 
5. Наумович О.Н. Становление высокотехнологического уклада в экономике Республики Беларусь. Автореферат на соискание ученой степени кандидата экономических наук по специальности 08.00.01 экономическая теория.- Минск: БГЭУ, 2014.

6. Нанотехнологии как ключевой фактор нового технологического уклада в экономике / С.Ю. Глазьев [и др.]; под ред. С.Ю. Глазьева, В.В. Харитонова. - М. : Тровант, 2009. - 304 с.

Статья поступила в редакиию 15 сентября 2016 года. 